\title{
Body condition score prior to parturition is associated with plasma and adipose tissue biomarkers of lipid metabolism and inflammation in Holstein cows
}

\author{
Abdulrahman Alharthi', Zheng Zhou ${ }^{2}$, Vincenzo Lopreiato ${ }^{1,3}$, Erminio Trevisi ${ }^{4}$ and Juan J. Loor ${ }^{1 *}$ (I)
}

\begin{abstract}
Background: Previous research has revealed a strong inflammatory response within adipose (AT) tissue during the transition into lactation. Whether this effect is a result of oxidative stress induced by lipolysis and fatty acid oxidation associated with differences in prepartum body condition score remains to be determined. The objectives of this study were to investigate systemic biomarkers of energy balance and inflammation and the expression of lipid metabolismand inflammation-related genes in AT during the transition period in dairy cows.
\end{abstract}

Results: Twenty multiparous Holstein cows were retrospectively divided by body condition score (BCS) prior to parturition into two groups (10 cows/group): BCS $\leq 3.25$ (LoBCS) and BCS $\geq 3.75$ (HiBCS). Subcutaneous adipose tissue was biopsied from the tail-head region at $d-10,7$ and 20 relative to parturition. Plasma was used to evaluate biomarkers of energy balance (EBAL) [free fatty acids (NEFA), glycerol, insulin] and inflammation [IL-1 $\beta$, haptoglobin, myeloperoxidase, and reactive oxygen metabolites (ROM)]. Although insulin concentration was not affected by BCS, NEFA was overall greater and glycerol lower in HiBCS cows. Greater activity of myeloperoxidase in plasma coincided with increased haptoglobin and IL-1 $1 \beta$ postpartum in LoBCS cows. Among genes related with oxidative stress, the expression of the cytosolic antioxidant enzyme SOD1 was greater in LOBCS compared to HiBCS. Cows in LOBCS compared with HiBCS had greater overall expression of ABDH5 and ATGL along with $A D I P O Q$, indicating enhanced basal lipolysis and secretion of adiponectin. Expression of CPT1A, ACADVL, and ACOX1 was greater overall in HiBCS than LoBCS indicating enhanced NEFA oxidation. Although the temporal increase in plasma NEFA regardless of BCS coincided with the profile of CPT1A, the gradual decrease in genes related with reesterification of NEFA (PCK1) and glycerol efflux (AQP7) coupled with an increase in glycerol kinase (GK) suggested some stimulation of NEFA utilization within adipose tissue. This idea is supported in part by the gradual decrease in insulin regardless of BCS. Although expression of the inflammation-related gene toll-like receptor 4 (TLR4) was greater in HiBCS versus LoBCS cows at $-10 \mathrm{~d}$, expression of TLR9 was greater in HiBCS versus LoBCS at $20 \mathrm{~d}$. These profiles did not seem to be associated with concentrations of pro-inflammatory biomarkers or ROM.

Conclusions: Overall, data indicated that cows with BCS 3.25 or lower before calving experienced greater alterations in systemic inflammation and basal lipolysis without excessive increases in NEFA plasma concentrations. Despite the greater plasma NEFA around parturition, cows with BCS 3.75 or higher seemed to have a more active system for catabolism of NEFA and utilization of glycerol within adipose tissue. A linkage between those pathways and risk of disorders postpartum remains to be determined.

Keywords: Body condition score, Lipid mobilization, Transition cow

\footnotetext{
* Correspondence: jloor@illinois.edu

${ }^{1}$ Mammalian NutriPhysioGenomics, Department of Animal Sciences and Division of Nutritional Sciences, University of Illinois, 1207 West Gregory Drive, Urbana, IL 61801, USA

Full list of author information is available at the end of the article
} 


\section{Background}

During the transition from a non-lactating to a lactating state, dairy cows are susceptible to metabolic disorders and immunologic challenges. Dry matter intake (DMI) decreases in the prepartum and rapidly declines when calving date approaches [1]. Due to the variation between DMI and nutrient requirements, most dairy cows will experience a period of negative energy balance (NEB) [2] that affects metabolism in different tissues, and particularly adipose [3]. Adipose tissue plays an important role in the maintenance of metabolic homeostasis during the transition period [4]. During late pregnancy and early lactation, the adipose tissue starts to break down to generate fatty acids (FA) and glycerol in a process known as lipolysis. The main purpose of lipolysis is to provide energy to other organs in the body. Lipolysis and lipogenesis in adipose tissue are regulated by different hormones around parturition [5]. Nonesterified fatty acid (NEFA) concentration in blood is a good indicator of adipose tissue mobilization [6].

After parturition in dairy cows, the mobilization of fat stored in adipose tissue leads to the loss in body condition score (BCS). Body condition score at calving and early lactation is related to the occurrence of several metabolic disorders like ketosis and fatty liver [7, 8]. It was reported that cows with high BCS at calving lose more body weight and body condition than cows with low BCS $[9,10]$. There is a relationship between obesity and oxidative stress in humans $[11,12]$. Bernabucci et al. [10] reported a connection between BCS, lipid mobilization and the imbalance in oxidative status in transition cows.

The primary objectives of this study were to evaluate the effect of BCS before calving on plasma and subcutaneous adipose tissue biomarkers of energy balance [free fatty acids (NEFA), glycerol, insulin] and inflammation [IL-1 $\beta$, haptoglobin, myeloperoxidase, and reactive oxygen metabolites (ROM)] during the transition period in dairy cows retrospectively grouped into a high or low BCS. The subcutaneous depot provides a readilyaccessible site for repeated sampling across time, and has been extensively used to understand metabolic mechanisms [4].

\section{Methods}

\section{Animals and treatments}

All the procedures for this study were conducted in accordance with a protocol approved by the Institutional Animal Care and Use Committee of the University of Illinois (Protocol \#13023). Twenty Holstein cows ( $n=$ 10/BCS group) were retrospectively selected according to $\mathrm{BCS}$ at calving: high $\mathrm{BCS}(3.75 \pm 0.12$; HiBCS $)$ or low BCS (3.25 \pm 0.15 ; LoBCS), based on a 5 -point scale [13]. All cows had ad libitum access to the same diet; from
-50 to $-22 \mathrm{~d}$ relative to calving they received a far-off diet (1.40 Mcal $/ \mathrm{kg}$ of DM, $10.2 \%$ RDP, and 4.1\% RUP), from $-21 \mathrm{~d}$ to calving they received a close-up diet $(1.52$ $\mathrm{Mcal} / \mathrm{kg}$ of DM, 9.1\% RDP, and 5.4\% RUP), and from calving until 30 DIM they received a lactation diet (1.71 $\mathrm{Mcal} / \mathrm{kg}$ of DM, 9.7\% RDP, and 7.5\% RUP) (Table 1). Diets were fed as a total mixed ration (TMR) once daily (06:30). Dry cows were housed in a free-stall barn with an individual Calan (American Calan, Northwood, NH,

Table 1 Ingredients and chemical composition of experimental diets

\begin{tabular}{|c|c|c|c|}
\hline \multirow[b]{2}{*}{ Ingredient, \% of DM } & \multicolumn{3}{|l|}{ Diet } \\
\hline & Far-off & Close-up & Lactation \\
\hline Alfalfa silage & 12.00 & 8.34 & 5.07 \\
\hline Alfalfa hay & - & 4.29 & 2.98 \\
\hline Corn silage & 33.00 & 36.40 & 33.41 \\
\hline Wheat straw & 36.00 & 15.63 & 2.98 \\
\hline Cottonseeds & - & - & 3.58 \\
\hline Wet brewers grains & - & 4.29 & 9.09 \\
\hline Ground shelled corn & 4.00 & 12.86 & 23.87 \\
\hline Soy hulls & 2.00 & 4.29 & 4.18 \\
\hline Soybean meal, 48\% CP & 7.92 & 2.57 & 2.39 \\
\hline Expeller soybean meal ${ }^{a}$ & - & 2.57 & 5.97 \\
\hline Soychlor ${ }^{b}$ & 0.15 & 3.86 & - \\
\hline Blood meal, 85\% CP & 1.00 & - & - \\
\hline ProVAAI AADvantage ${ }^{c}$ & - & 0.86 & 1.50 \\
\hline Urea & 0.45 & 0.30 & 0.18 \\
\hline Rumen-inert fat $^{d}$ & - & - & 1.02 \\
\hline Limestone & 1.30 & 1.29 & 1.31 \\
\hline Salt & 0.32 & 0.30 & 0.30 \\
\hline Dicalcium phosphate & 0.12 & 0.18 & 0.30 \\
\hline Magnesium oxide & 0.21 & 0.08 & 0.12 \\
\hline Magnesium sulfate & 0.91 & 0.99 & - \\
\hline Sodium bicarbonate & - & - & 0.79 \\
\hline Potassium carbonate & - & - & 0.30 \\
\hline Calcium sulfate & - & - & 0.12 \\
\hline Mineral vitamin mix & 0.20 & 0.17 & 0.18 \\
\hline Vitamin $A^{f}$ & 0.015 & - & - \\
\hline Vitamin $D^{g}$ & 0.025 & - & - \\
\hline Vitamin $E^{\mathrm{h}}$ & 0.38 & 0.39 & - \\
\hline Biotin & - & 0.35 & 0.35 \\
\hline
\end{tabular}

${ }^{a}$ SoyPLUS (West Central Soy, Ralston, IA)

${ }^{\mathrm{b}}$ By West Central Soy

'Perdue AgSolutions LLC (Ansonia, OH)

${ }^{\mathrm{d} E n e r g y ~ B o o s t e r ~} 100$ (Milk Specialties Global, Eden Prairie, MN)

${ }^{\mathrm{e}}$ Contained a minimum of $5 \% \mathrm{Mg}, 10 \% \mathrm{~S}, 7.5 \% \mathrm{~K}, 2.0 \% \mathrm{Fe}, 3.0 \% \mathrm{Zn}, 3.0 \% \mathrm{Mn}$,

$5,000 \mathrm{mg}$ of $\mathrm{Cu} / \mathrm{kg}, 250 \mathrm{mg}$ of $\mathrm{I} / \mathrm{kg}, 40 \mathrm{mg}$ of Co/kg, $150 \mathrm{mg}$ of Se/kg, 2,200

$\mathrm{kIU}$ of vitamin $\mathrm{A} / \mathrm{kg}, 660 \mathrm{kJU}$ of vitamin $\mathrm{D}_{3} / \mathrm{kg}$, and $7,700 \mathrm{IU}$ of vitamin $\mathrm{E} / \mathrm{kg}$

${ }^{f}$ Contained $30,000 \mathrm{klU} / \mathrm{kg}$

${ }^{9}$ Contained $5009 \mathrm{kIU} / \mathrm{kg}$

${ }^{\mathrm{h}}$ Contained $44,000 \mathrm{klU} / \mathrm{kg}$ 
USA) gate feeding system. Cows had access to sandbedded free stalls until $3 \mathrm{~d}$ before expected calving date, when they were moved to an individual maternity pen bedded with straw until they calved. After calving, cows were housed in a tie-stall barn and were fed a common lactation TMR in their individual feed bunks once daily in the morning, and milked 3 times daily at approximately 6:00, 14:00, and 22:00.

\section{Adipose tissue}

Subcutaneous adipose tissue biopsies were collected from the tail-head region at $-10,7$ and $20 \mathrm{~d}$ relative to parturition as described by Ji et al. [14]. The samples were immediately frozen in liquid nitrogen and transferred to a $-80{ }^{\circ} \mathrm{C}$ freezer for future analysis.

\section{Blood plasma biomarkers}

The concentrations of indicators of energy balance including free fatty acids (Cat No. 7 00310, Cayman Chemical Company, Ann Arbor, MI), glycerol (Cat No.10010755, Cayman Chemical Company, Ann Arbor, MI), and insulin (Cat No. 10-1201-01, Mercodia AB, Uppsala, Sweden) were analyzed using commercial kits according to the manufacturer's protocols. The proinflammatory cytokine IL- $1 \beta$ was measured using a bovine ELISA (Cat. No. ESS0027; Thermo Scientific, Rockford, IL). Haptoglobin, myeloperoxidase, and ROM were measured using kits purchased from Instrumentation Laboratory (Lexington, MA) following the procedures described previously using the clinical autoanalyzer (ILAB 600, Instrumentation Laboratory).

\section{RNA extraction, PCR, and design and evaluation of primers \\ RNA extraction}

The frozen tissues were used to extract the RNA using protocols established in our laboratory [15]. Briefly, adipose tissue samples were weighed $(\sim 0.2-0.4 \mathrm{~g})$ and immediately placed in $1.2 \mathrm{~mL}$ of ice-cold Qiazol reagent (Qiagen 75842; Qiagen Inc., Valencia, CA) for homogenization. After homogenization, genomic DNA was removed from RNA with DNase using RNeasy Mini Kit columns (Qiagen, Hilden, Germany). The NanoDrop ND-1000 spectrophotometer (Nano-Drop Technologies, Wilmington, DE, USA) was used to measure the concentration of RNA, while the quality of RNA was evaluated using the Agilent Bioanalyzer system (Agilent 2100 Bioanalyzer, Agilent Technologies, Santa Clara, CA, USA). The RNA integrity number averaged $7.33 \pm$ 1.10 .

\section{qPCR analysis}

Primer pairs were designed using the NCBI PrimerBLAST tool, and tested through normal PCR, using the same thermo cycle as the final qPCR analysis, and gel electrophoresis to verify the presence of a single PCR product of the expected size. The product was then purified and sent for sequencing at the University of Illinois Core Sequencing Facility, to assess amplification of the correct target.

The cDNA was synthesized with 100 ng RNA. The RNA was mixed with the Master Mix-1 (MM1) containing $9 \mu \mathrm{L}$ DNase/RNase free water and $1 \mu \mathrm{L}$ random primers $\left(\right.$ Roche $^{\circ}$ Cat. No. 11034731 001, Roche Diagnostics GmbH, Mannheim, Germany), then incubated at $65{ }^{\circ} \mathrm{C}$ for $5 \mathrm{~min}$ and kept in ice for $3 \mathrm{~min}$. The reaction was performed using the Eppendorf Mastercycler ${ }^{\circ}$. Nine $\mu \mathrm{L}$ of Master Mix-2 (MM2) consisting of $1.625 \mu \mathrm{L}$ DNase/RNase free water, $4 \mu \mathrm{L} 5 \times$ First-Strand Buffer, $1 \mu \mathrm{L}$ Oligo dT18, $2 \mu \mathrm{L} 10 \mathrm{mmol} / \mathrm{L}$ dNTP mix (10 mmol/L; Cat. No. 18427-088; Invitrogen), $0.25 \mu \mathrm{L}$ of Revert aid (200 IU/ $\mu \mathrm{L}$; Cat. No. EP 0441; Fermentas), and $0.125 \mu \mathrm{L}$ of RNase inhibitor $(20 \mathrm{U} / \mu \mathrm{L}$; Cat. No. EO 0382; Fermentas). Samples were then incubated (MM1 + RNA and MM2) at the following temperature program: $25{ }^{\circ} \mathrm{C}$ for $5 \mathrm{~min}, 42{ }^{\circ} \mathrm{C}$ for $60 \mathrm{~min}$ and $70{ }^{\circ} \mathrm{C}$ for $5 \mathrm{~min}$. An aliquot of undiluted cDNA from all samples was pooled to make the standard curve by diluting with DNase/RNase free water, then the cDNA was diluted 1:4 with DNase/RNase free water.

Quantitative PCR was performed using $4 \mu \mathrm{L}$ diluted cDNA combined with $6 \mu \mathrm{L}$ of a mixture containing $5 \mu \mathrm{L}$ $1 \times$ SYBR Green master mix (Applied Biosystems, CA, USA), $0.4 \mu \mathrm{L}$ each of $10 \mu \mathrm{mol} / \mathrm{L}$ forward and reverse primers, and $0.2 \mu \mathrm{L}$ DNase/RNase free water in a MicroAmp $^{\text {ts }}$ Optical 384-Well Reaction Plate (Applied Biosystems, CA, USA). An ABI prism 7900 HT SDS instrument was used at the following temperature program: 2 min at $50{ }^{\circ} \mathrm{C}, 10 \mathrm{~min}$ at $95{ }^{\circ} \mathrm{C}, 40$ cycles of $15 \mathrm{~s}$ at $95{ }^{\circ} \mathrm{C}$, and $1 \mathrm{~min}$ at $60{ }^{\circ} \mathrm{C}$. The presence of a single PCR product was verified by the dissociation protocol using incremental temperatures to $95{ }^{\circ} \mathrm{C}$ for $15 \mathrm{~s}$ plus $65{ }^{\circ} \mathrm{C}$ for $15 \mathrm{~s}$. Gene symbols, ID, and accession numbers of PCR primers are reported in Additional file 1: Table S1. The sequencing products were validated through BLASTN at the National Center for Biotechnology Information (NCBI) database (Additional file 1: Table S2).

The final data were normalized using the geometric mean of three internal control genes: $U X T, G A P D H$ and RPS9 previously validated by our group [16, 17]. The relative mRNA abundance was calculated as previously reported [18] using the median $\Delta \mathrm{Ct}(\Delta \mathrm{Ct}=\mathrm{Ct}$ of the gene - geometrical mean $\mathrm{Ct}$ of internal control genes) corrected by efficiency (E), where \% relative mRNA abundance $=\left[1 / \mathrm{E}^{\Delta \mathrm{Ct}}\right] / \Sigma\left[1 / \mathrm{E}^{\Delta \mathrm{C}}\right]$ all measured genes $\times$ 100 (Additional file 1: Table S3). The PCR efficiency was calculated for each gene using the standard curve method $\left[\mathrm{E}=10^{(-1 / \text { slope })}\right]$. 


\section{Statistical analysis}

After data normalization with the geometric mean of the internal control genes, the quantitative PCR data were $\log _{2}$ transformed before statistical analysis to obtain a normal distribution. $\log _{2}$ transformed data were subjected to ANOVA and analyzed using repeated measures in PROC MIXED of SAS (SAS Institute, Inc., Cary, NC, USA). The statistical model included Day (-10, 7 and 20 $\mathrm{d}$ relative to parturition), BCS (HiBCS and LoBCS), and their interactions $(\mathrm{BCS} \times \mathrm{Day})$ as fixed effects, and cow within BCS group as random effect. The analysis of DMI (carried out separately for pre- and post-calving periods), milk yield, and plasma biomarker data was performed with the same model for gene expression analysis. For DMI and milk yield the time effect included all $\mathrm{d}$ within each period (from -22 to $-1 \mathrm{~d}$ for pre-calving, and 1 to $30 \mathrm{~d}$ for post-calving). Furthermore, BCS data (as units of change between -3 and 3 wk relative to parturition) were analyzed with the PROC MIXED of SAS with BCS group as fixed effect. Data were considered significant at $P \leq 0.05$ and tendencies at $P \leq 0.15$.

\section{Results}

Dry matter intake, milk production, and BCS

There was no overall effect of BCS on milk yield or DMI (Fig. 1). However, the HiBCS group experienced a higher loss of BCS than the LoBCS group $(P<0.01$; Fig. 2$)$ between -3 and 3 wk relative to calving.

\section{Plasma biomarkers of energy balance}

The concentration of free fatty acids (NEFA) was greater overall for HiBCS cows, particularly due to differences at $-10 \mathrm{~d}$ from parturition (Fig. 3). In contrast, concentrations of glycerol were fairly stable around parturition but were lower in HiBCS cows. There was a BCS $\times$ Day effect $(P=0.05)$ for concentration of insulin namely due to the decrease in concentration at 7 and $20 \mathrm{~d}$ postpartum compared with $-10 \mathrm{~d}$.

\section{Plasma biomarkers of inflammation and oxidative stress}

The concentration of the positive acute-phase protein haptoglobin had a $\mathrm{BCS} \times$ Day effect $(P=0.05)$ namely due to a gradual increase in concentration at $20 \mathrm{~d}$ for LoBCS cows compared with a gradual decrease for HiBCS cows (Fig. 4). This response in LoBCS cows mirrored the activity of myeloperoxidase, an enzyme secreted by activated immune cells (e.g. neutrophils), which was greater overall in LoBCS cows. The concentration of the pro-inflammatory cytokine IL-1 $\beta$ was fairly constant around parturition, and tended to be greater in LoBCS cows $(P=0.09)$. No effect of BCS $(P=0.98)$ was detected for concentration of ROM, but there was a gradual increase between -10 and $20 \mathrm{~d}$ around parturition.
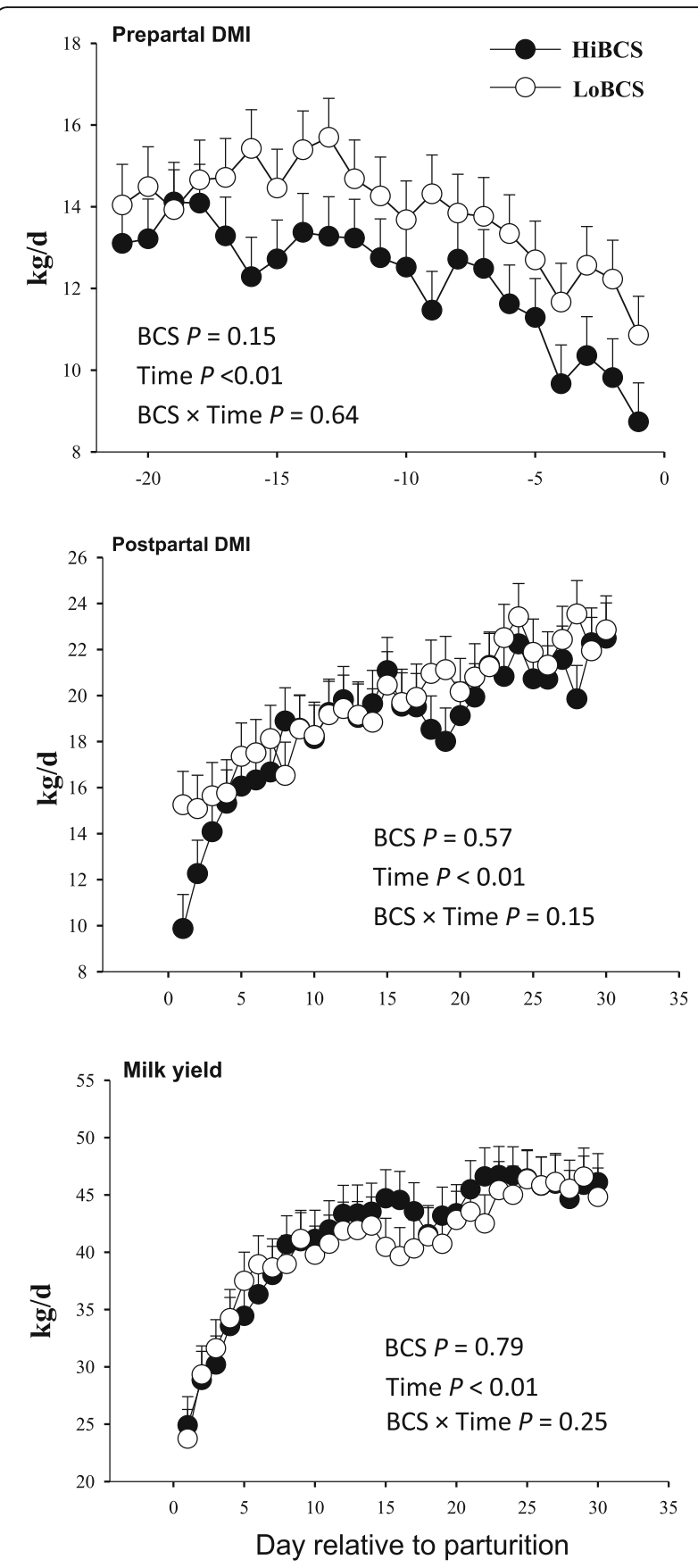

Fig. 1 Daily dry matter intake from -21 through $30 \mathrm{~d}$ around parturition (top panels), and daily milk yield (kg/d) (least squares mean \pm SEM) in cows with high body condition score (HiBCS) or low body condition score (LoBCS) at parturition

Genes involved in lipolysis and adipokine synthesis The expression of ATGL (which catalyzes the first step in triglyceride hydrolysis) and LIPE was affected by BCS $(P<0.05)$, with $A T G L$ having greater overall expression in LoBCS than HiBCS cows (Fig. 5). There was a strong tendency for an interaction effect on expression of $L I P E$ 


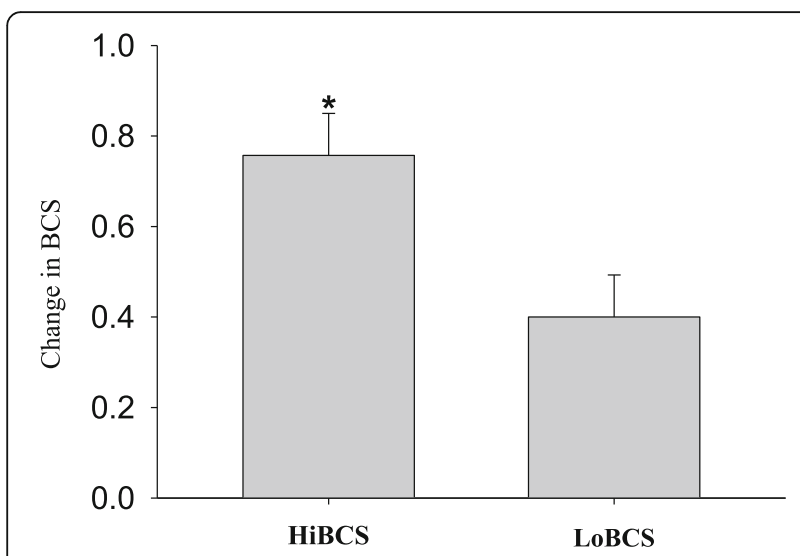

Fig. 2 Change in body condition score (BCS) units between -3 and 3 wk relative to parturition in cows with high body condition score (HiBCS) or low body condition score (LOBCS) at parturition. *Groups differ $(P \leq 0.05)$

(BCS $\times$ Day, $P=0.07$ ) due to upregulation at $\mathrm{d} 7$ and 20 in LoBCS than HiBCS cows. An overall greater expression of $A B D H 5(P=0.04)$ was detected in LoBCS cows. The gene encoding the adipokine adiponectin (ADIPOQ) was affected by BCS due to greater expression in LoBCS than HiBCS cows $(P \leq 0.05)$.

\section{Fatty acid oxidation and transport genes}

There was an interaction (BCS $\times$ Day, $P \leq 0.05)$ for CPT1A (a key enzyme in fatty acid oxidation) due to greater expression at -10 and $7 \mathrm{~d}$ in HiBCS compared with LoBCS cows (Fig. 6). There was no BCS or BCS $\times$ Day effect for the expression of CPT2. However, HiBCS cows experienced a gradual increase (time, $P=0.05$ ) between -10 and $20 \mathrm{~d}$. Acyl-CoA dehydrogenase very long chain $(A C A D V L)$ (also involved in oxidation of long chain fatty acids) was greater in HiBCS than LoBCS cows across time $(P \leq 0.05)$. There was a significant interaction $(\mathrm{BCS} \times$ Day $P \leq 0.05)$ due to higher expression at -10 and $7 \mathrm{~d}$ in HiBCS than LoBCS cows. Similar to $A C A D V L$, there was a BCS $(P \leq 0.05)$ effect for $A C O X 1$ due to greater overall expression in $\mathrm{HiBCS}$ cows.

\section{Transporter and fatty acid binding protein gene expression}

The expression of solute carrier family 16 member 1 (SLC16A1; Fig. 7), involved in short-chain fatty acid transport, was affected by BCS $(P \leq 0.05)$ due to greater expression in LoBCS than HiBCS cows. We observed a Day effect $(P=0.04)$ for $F A B P 4$ due to higher expression in both LoBCS and HiBCS groups at $7 \mathrm{~d}$ (Fig. 5). The expression of the glycerol transporter $A Q P 7$ was not affected by BCS or BCS $\times$ Day, but there was a Day effect $(P \leq 0.05)$ due to a decrease in expression in both groups between -10 and $20 \mathrm{~d}$ (Fig. 7).

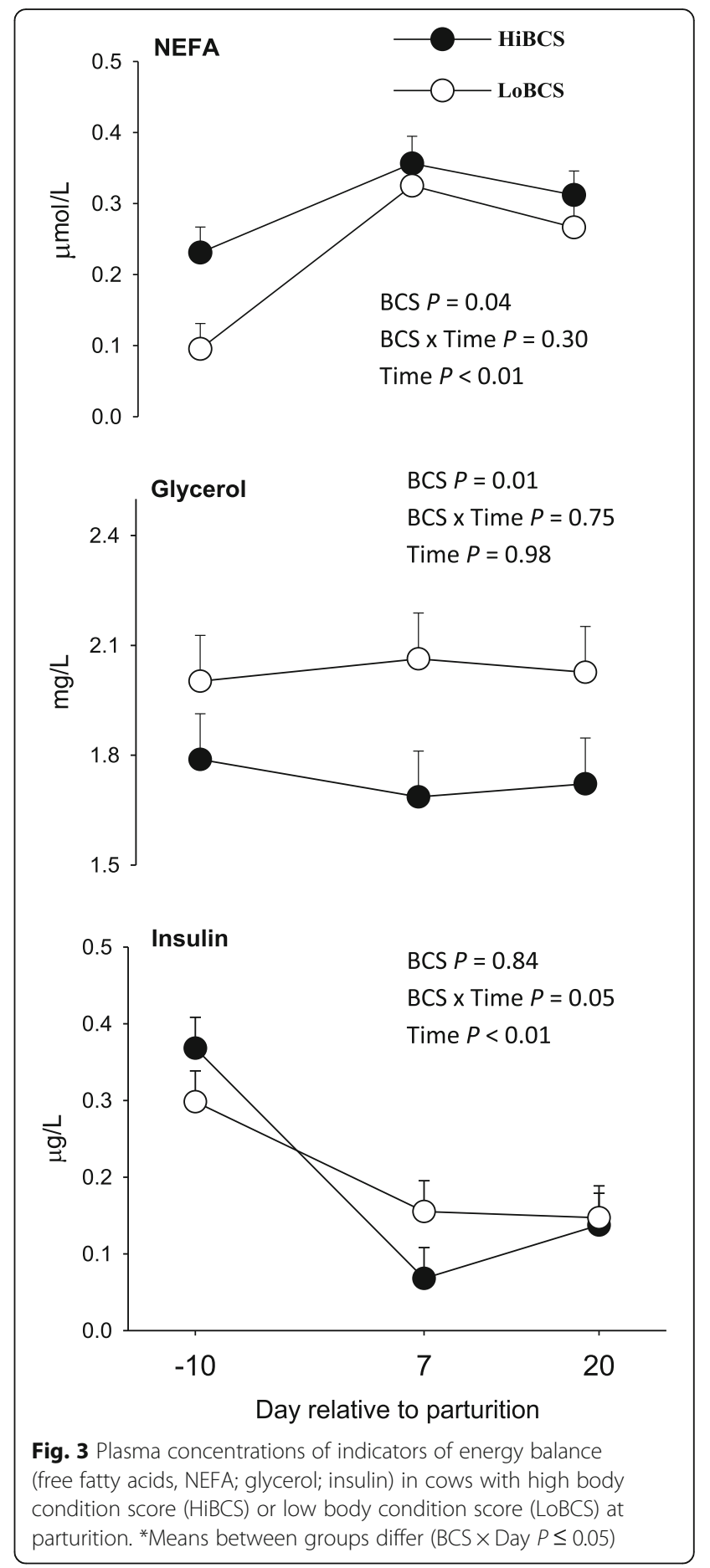

Glyceroneogenic gene expression

The expression of PCK1 (which plays an important role in glyceroneogenesis) was overall greater in LoBCS $(P<0.01)$ than HiBCS cows (Fig. 8). However, both groups had higher $P C K 1$ expression $(P<0.01)$ in the pre-calving compared with post-calving period. Glycerol kinase $(G K)$ was not affected by BCS, but there was a Day effect $(P \leq 0.05)$ due to an increase in 


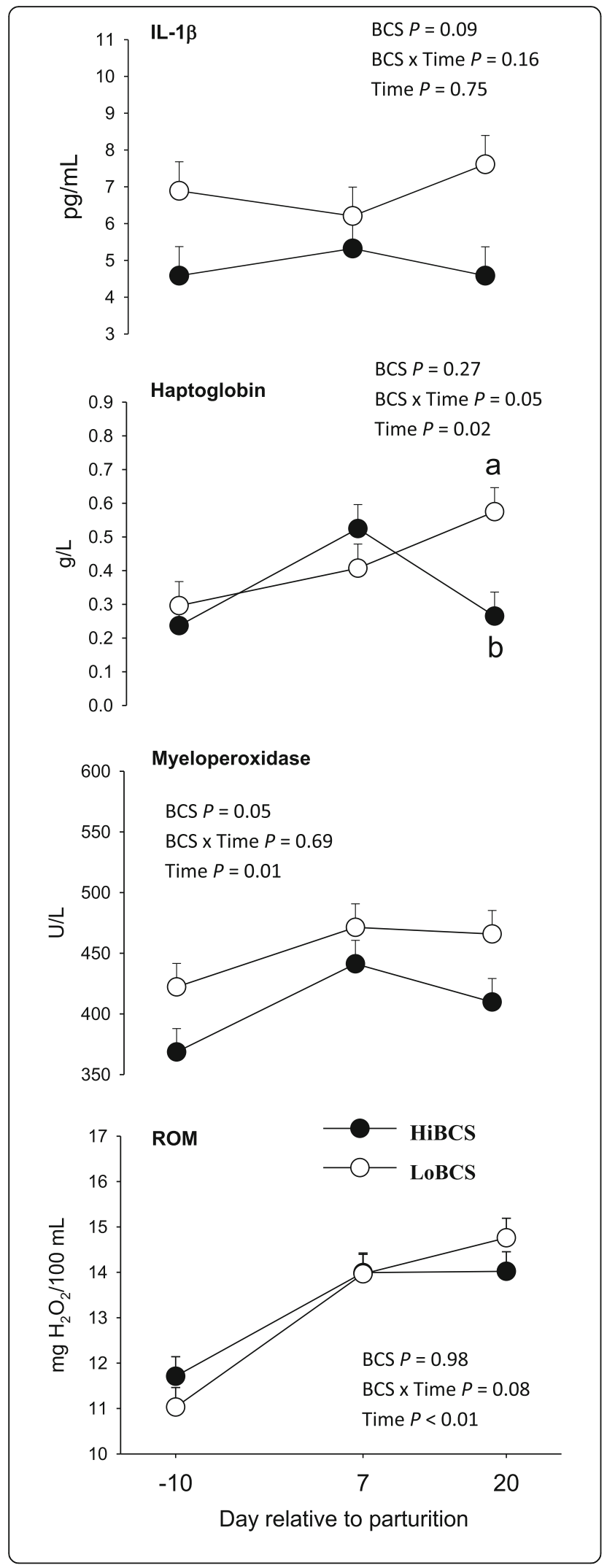

Fig. 4 Plasma concentrations of indicators of inflammation (IL-1 $\beta$, haptoglobin, and myeloperoxidase) and oxidative stress (reactive oxygen metabolites, ROM) energy balance (free fatty acids, NEFA; glycerol; insulin) in cows with high body condition score (HiBCS) or low body condition score (LoBCS) at parturition. ${ }^{\mathrm{a}, \mathrm{b}}$ Means between groups differ $(\mathrm{BCS} \times$ Time $P \leq 0.05)$

expression at 7 and $20 \mathrm{~d}$ compared with $-10 \mathrm{~d}$ in both HiBCS and LoBCS.

\section{Inflammation and oxidative stress gene expression}

The expression of NFE2L2 (a transcription regulator involved in oxidative stress and inflammation) was not affected by BCS, Day or their interaction (Fig. 9). We detected a BCS effect $(P \leq 0.05)$ for SOD1 due to higher expression in LoBCS cows at -10 and $7 \mathrm{~d}$. There was an interaction $(\mathrm{BCS} \times \mathrm{Day}, P \leq 0.05)$ observed for the mitochondrial enzyme $S O D 2$ because of greater expression at d 7 in LoBCS than HiBCS cows. Although Toll-Like Receptor 4 (TLR4) was not affected by BCS or time, we observed an interaction resulting in higher expression at $-10 \mathrm{~d}$ in HiBCS cows. We detected a BCS effect for the expression of TLR9 $(P \leq 0.05)$ because of an increase in the expression at $20 \mathrm{~d}$ in HiBCS compared with LoBCS cows.

\section{Discussion}

Around calving, adipose tissue becomes active by increasing the mobilization of body fat reserves to provide energy to other tissues. Adipose triglyceride lipase (ATGL) is the rate-limiting enzyme of lipolysis and is upregulated during fasting partly through transcription [19]. The degradation of triacylglycerol (TAG) is regulated by ATGL and LIPE, the two key enzymes in basal and stimulated lipolysis [20]. The complete activation of ATGL requires binding of the protein ABHD5 which is the activator of ATGL [14]. Hormone sensitive lipase (LIPE) is able to hydrolyze TAG, with the activation of LIPE occurring via cyclic AMP as a result of betaadrenergic stimulation (i.e. post-translational regulation) [21]. Thus, although opposite to what would be expected, the greater expression of ATGL, LIPE and $A B D H 5$ in LoBCS compared with HiBCS cows indicated a greater state of basal and stimulated lipolysis over time. Clearly, cows with HiBCS would be expected to have accumulated more fat depots and potentially have greater lipolytic activity partly through the action of ATGL and LIPE [14]. Although those cows had greater plasma NEFA primarily prior to calving, despite the gradual increase in NEFA postpartum the glycerol concentration was lower throughout the transition period. Thus, alternate mechanisms within adipose tissue seem to account for differences between lipolytic marker genes and systemic indicators. 


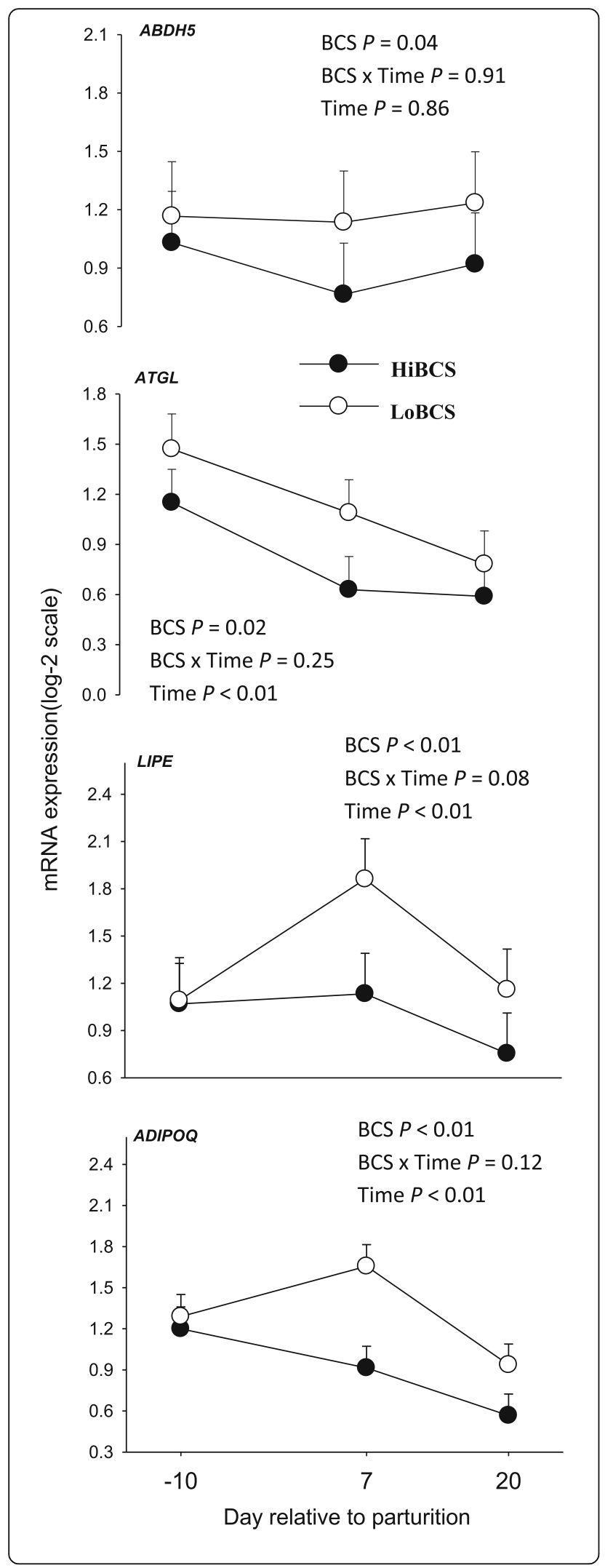

Fig. 5 mRNA expression (least squares mean \pm SEM) of genes involved in basal (ABDH5, ATGL) and stimulated (LIPE) lipolysis and the anti-lipolytic adipokine adiponectin (ADIPOQ) lipolysis in cows with high body condition score (HiBCS) or low body condition score (LoBCS) at parturition

In the context of energy balance around parturition, the greater expression of $A D I P O Q$ in the LoBCS cows is not intuitive because in non-ruminant obese subjects concentration of adiponectin in the circulation is lower due in part to a decrease in transcription [22]. It could be speculated that a lower circulating concentration of adiponectin in obese states or a high BCS triggers a response within adipose tissue to upregulate $A D I P O Q$, hence, its availability to peripheral tissues. Overall, the $A D I P O Q$ data agree with a previous report of a negative correlation between BCS and serum adiponectin concentration [23].

Both the adipose tissue sensitivity to insulin and its concentration affect the degree of lipolysis and lipogenesis [24]. Data from rats and humans demonstrated that late-pregnancy is an insulin-resistant state [25]. The greater mRNA expression of CPT1A, ACADVL and $A C O X 1$ (genes involved in FA oxidation) in HiBCS cows indicated an increase in the use of NEFA as energy sources within adipose tissue, either through mitochondrial or peroxisomal $\beta$-oxidation. At least in nonruminants, the activity of these enzymes is partly regulated via changes in transcription [26]. Despite the increase in FA release from adipose tissue after calving regardless of $\mathrm{BCS}$, ensuring that tissues like liver or muscle could oxidize them for energy [27], the present data underscore a capacity of adipose for utilization of endogenously-released FA. Furthermore, the greater lipolytic gene expression indicated that LoBCS cows likely were mobilizing more TAG than $\mathrm{HiBCS}$ but at the same time they did not seem to have the ability to increase the utilization of these FA through oxidation. Because in non-ruminant cells solute carrier family 16 member 1 (SLC16A1) is controlled through transcription [28], we speculate that the upregulation of in LoBCS cows might have increased uptake of short chain monocarboxylates such as pyruvate, lactate and/or volatile fatty acids. As such, adipocytes would not have required increased oxidation of FA to generate energy.

Aquaglyceroporin aquaporin-7 (AQP7) is highlyexpressed in non-ruminant adipose tissue, and helps facilitate the efflux of glycerol that is released from adipose tissue during lipolysis. A reduction in transcription of AQP7 is related to TAG accumulation in adipose tissue [29] and a lower plasma concentration of glycerol under fasting and fed conditions [30]. The sharp decrease in $A Q P 7$ expression between prepartum and postpartum agrees with the only published study in 


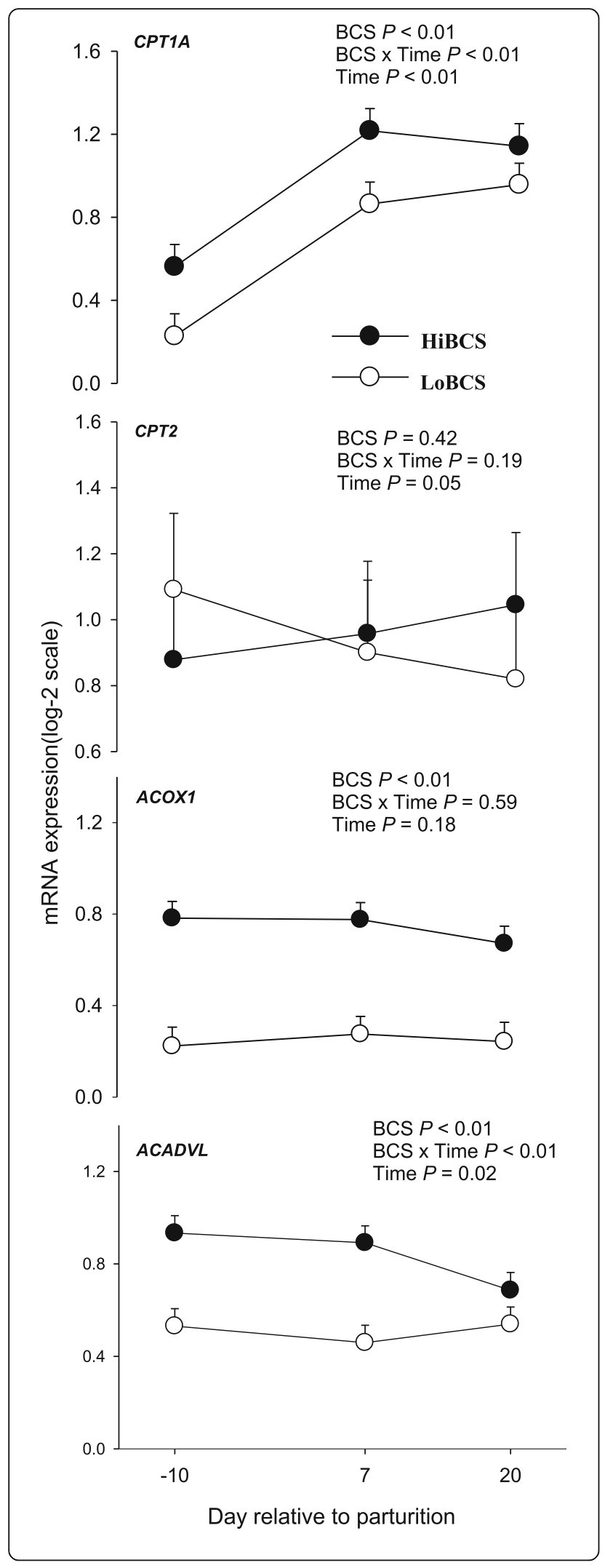

Fig. 6 mRNA expression (least squares mean \pm SEM) of genes involved in fatty acid oxidation (CPT1A, CPT2, ACOX1, ACADVL) in cows with high body condition score (HiBCS) or low body condition score (LoBCS) at parturition. * Means between groups differ $(\mathrm{BCS} \times$ Day $P \leq 0.05)$

periparturient dairy cows [31], but was unrelated with plasma glycerol concentrations which were stable around parturition. The fact that bovine adipocyte size and $A Q P 7$ mRNA expression are negatively correlated [31] agrees with observations from McNamara [4] demonstrating a marked reduction in adipocyte size after calving, and also data from AQP7-null mice in which body fat mass increased as a result of adipocyte hypertrophy [32]. Despite the lack of association between AQP7 and plasma glycerol, the available data in dairy cows seem to indicate a functional role for AQP7 in adipocyte biology. It could be possible that plasma glycerol concentration is partly regulated by its use in the liver during gluconeogenesis [6].

Transcription of PCK1 is related to glyceroneogenesis (i.e. de novo synthesis of glycerol-3-phosphate for TAG production) in non-ruminants [33], and we speculate that the greater expression of PCK1 in LoBCS cows could have been a response to help re-esterify FA released as a result of greater ATGL and LIPE in those cows. Mechanistically, such response would make sense given that a high rate of FA recycling during lipolysis can help maintain normal intracellular concentrations of FA when enough energy has been generated through oxidation [33]. It is possible that recycling of the excess amount of FA that were hydrolyzed after calving in LoBCS cows was partly regulated by hormonal signals (e.g. epinephrine) and the upregulation of glycerol kinase (GK) (a transcriptional target of PPARGC- $1 \alpha$ in nonruminant adipocytes) as a way to maintain TAG stores in those cows. Comparing -3 wk versus 3 wk relative to parturition reveals that HiBCS cows lost more body condition, which supports the role of PCK1 in maintaining TAG stores.

Oxidative stress, resulting in the increase in ROM production, can cause alterations of cell membranes and changes in cellular function [34, 35]. The enzyme superoxide dismutase (SOD) catalyzes an antioxidant mechanism that decreases concentration ROM, hence, plays an important role in maintenance of proper antioxidant capacity in tissues [36]. It was previously reported that cows with high BCS before calving and with more BCS losses had lower SOD activity and higher ROM in the circulation [10]. Furthermore, several studies in humans linked obesity with higher oxidant and lower antioxidant concentrations $[37,38]$. Because a previous study detected that the inhibition of $S O D 2$ expression caused accumulation of ROM [39], we speculate that the greater 


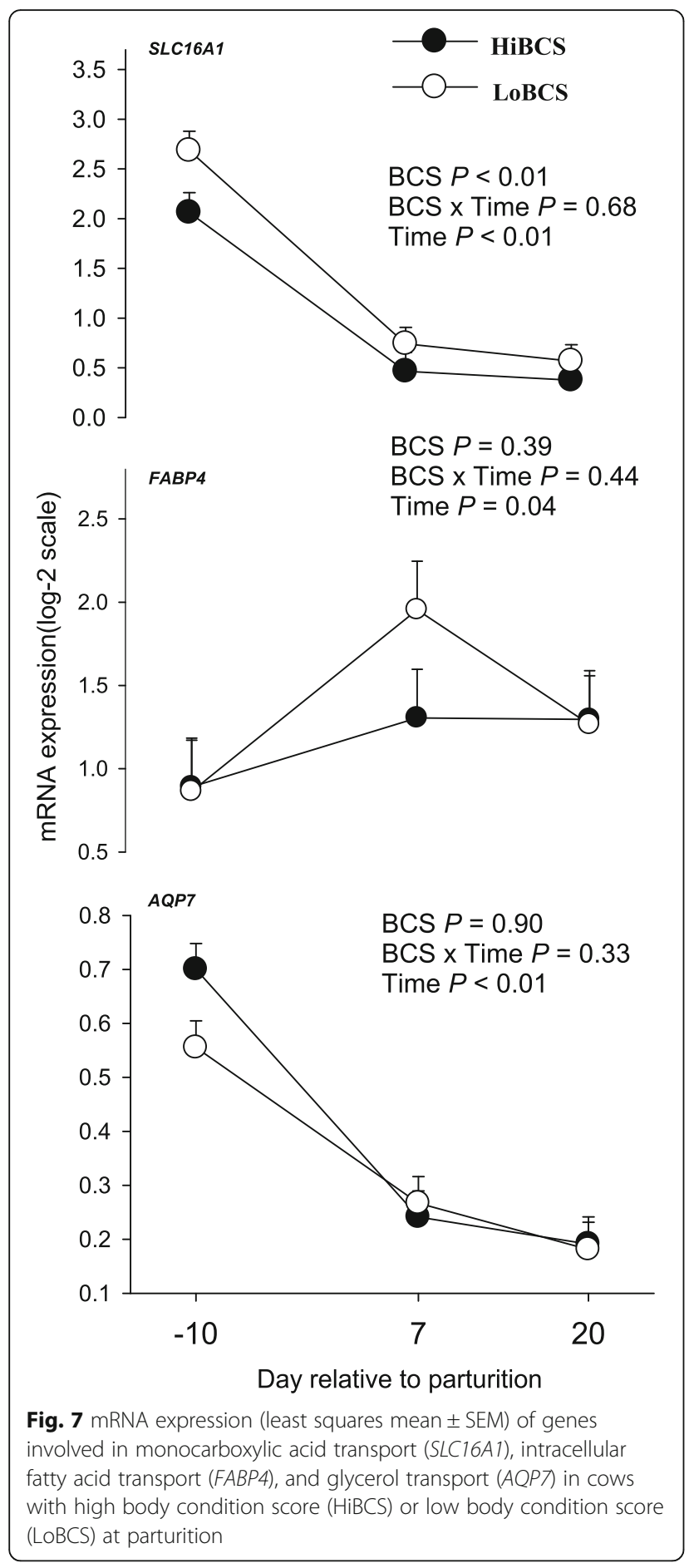

expression of SOD1 in LoBCS cows could have helped the adipose tissue maintain a proper antioxidant status. Although plasma ROM did not differ due to BCS, concentrations increased gradually during the transition period and is unknown if they could affect adipose tissue. From a mechanistic standpoint, however, it could be possible that the greater ATGL and LIPE in LoBCS cows

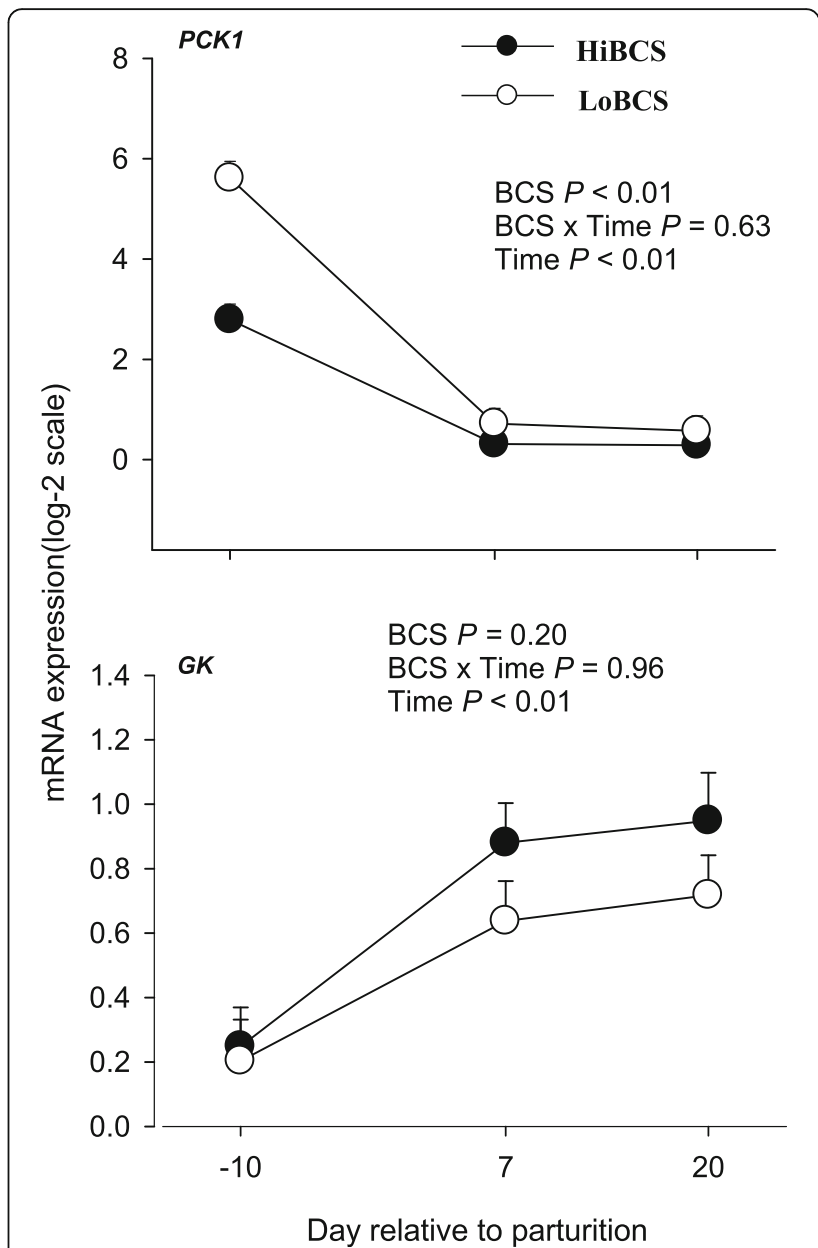

Fig. 8 mRNA expression (least squares means \pm SEM) of genes involved in glycerol-3-phosphate synthesis (phosphoenolpyruvate carboxykinase 1, PCK1; glycerol kinase, GK) in cows with high body condition score (HiBCS) or low body condition score (LoBCS) at parturition

could have generated more FA and greater concentrations of ROM.

Toll-like receptors are essential in the defense mechanism against microbes and activate the innate immune response during inflammation [40]. Greater overall expression of TLR9 in HiBCS compared with LoBCS and greater expression of TLR4 at day -10 in the same group of cows indicated a more pronounced localized state of inflammation. Toll-like receptor 4 binds to bacterial lipopolysaccharide which is the main component of all Gram-negative bacteria [41]. Also, TLR4 could be activated via saturated fatty acids [42] and such response could be a reason for the increase in expression of TLR4 in HiBCS. Because the systemic concentrations of inflammatory biomarkers indicated a more pronounced response in LoBCS cows, it would seem that the adipose tissue depot has an independent mechanism (at least from the transcriptional standpoint) to control this 


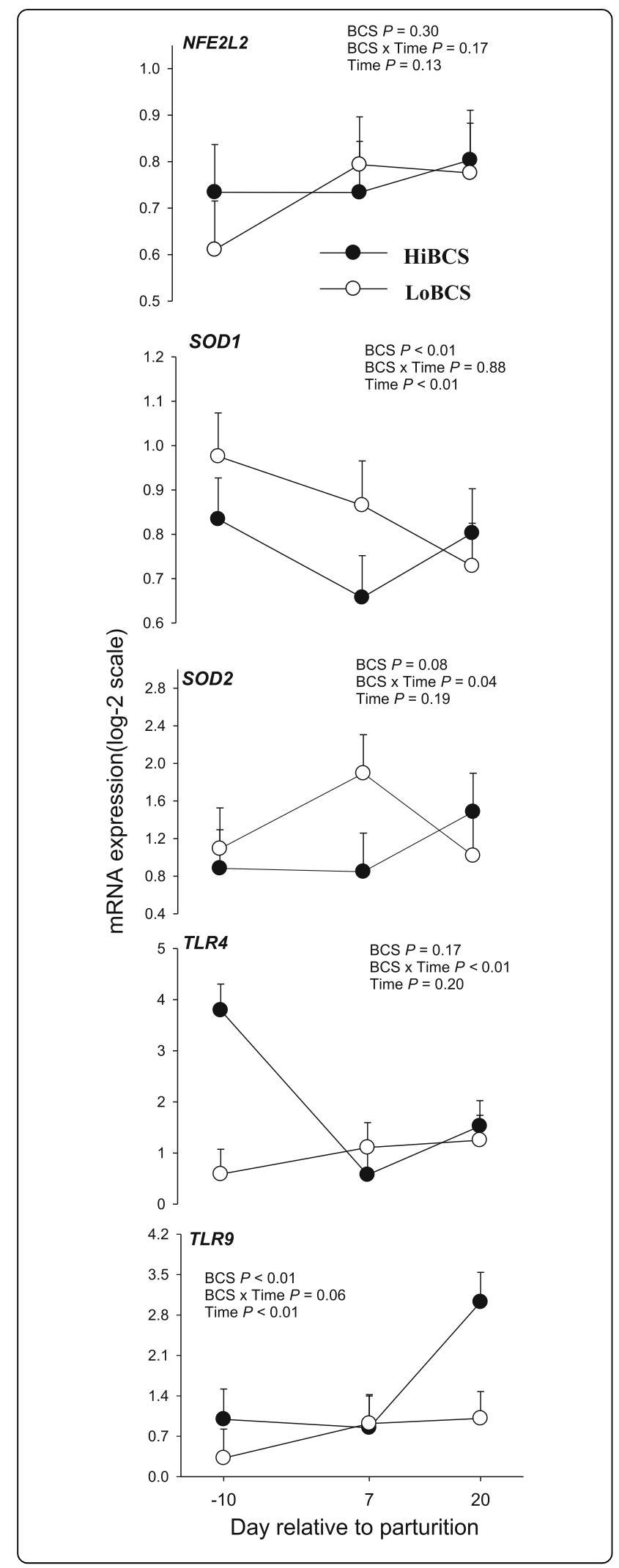

Fig. 9 mRNA expression (least squares means \pm SEM) of genes involved in inflammation and oxidative stress in cows with high body condition score (HiBCS) or low body condition score (LoBCS) at parturition. *Means between groups differ $(B C S \times$ Day $P \leq 0.05)$

process. The identity of such mechanisms are unclear; however, a recent study in mice demonstrated that obesity is associated with the release of cell-free DNA (cfDNA) which could stimulate the resident macrophages via the TLR9 pathway [43]. Further research could help demonstrate if the same linkage exists in dairy cow adipose tissue.

\section{Conclusions}

The greater expression of genes associated with lipolysis in LoBCS cows indicated a greater state of basal lipolysis in this group, and at the same time those cows had higher expression of PCK1, which indicated more reesterification of FA to maintain TAG stores. The greater expression of genes involved in FA oxidation in the HiBCS indicated a higher (and potentially more efficient) use of FA as energy substrates within adipose tissue. However, the greater expression of TLR4 and TLR 9 in HiBCS cows and the lower expression of SOD in the same group could be associated with the observed higher loss of BCS postpartum. Whether this inflammatory status within adipose tissue elicits positive or negative effects remains to be established.

\section{Additional file}

Additional file 1: Table S1. Gene accession number, symbol, and forward and reverse sequences. Table S2. Sequencing results obtained from PCR products. Table S3. qPCR performance of genes measured in subcutaneous adipose tissue. (DOCX 19 kb)

\section{Abbreviations}

BCS: body condition score; DMI: dry matter intake; FA: fatty acid; HiBCS: high BCS; LoBCS: low BCS; NEFA: free fatty acid; QPCR: quantitative polymerase chain reaction; RIN: RNA integrity number; TMR: total mixed ration

\section{Acknowledgments}

Abdulrahman Alharthi is a recipient of fellowship from King Saud University to perform his PhD studies at the University of Illinois (Urbana). Zheng Zhou was recipient of a fellowship from China Scholarship Council (CSC) to perform his PhD studies at the University of Illinois (Urbana).

\section{Funding}

Not applicable.

\section{Availability of data and materials}

The datasets during and/or analyzed during the current study are available from the corresponding author on reasonable request.

\section{Authors' contributions}

$A A, V L, Z Z$, and ET performed analyses and analyzed data. JJL conceived the animal experiment. $A A, V L$, and $J J L$ wrote the manuscript. All authors approved the final version of the manuscript. 


\section{Authors' information}

A. Alharthi, PhD student, University of Illinois, Urbana, Illinois, 61,801, USA. Z. Zhou is Assistant Professor, Animal and Veterinary Sciences, Clemson University, 146 Poole Agricultural Center, Clemson, SC 29634, USA. V. Lopreiato, PhD student, Magna Græcia University of Catanzaro, Catanzaro, 88,100, Italy. E. Trevisi is Associate Professor at the Institute of Zootechnics, Faculty of Agriculture, Food and Environmental Science, Università Cattolica del S. Cuore, Piacenza, 29,122, Italy. J. J. Loor is Associate Professor in the Department of Animal Sciences, University of Illinois, Urbana, Illinois, 61,801, USA

\section{Ethics approval and consent to participate}

Not applicable.

\section{Consent for publication}

Not applicable.

\section{Competing interests}

The authors declare that they have no competing interests.

\section{Author details}

${ }^{1}$ Mammalian NutriPhysioGenomics, Department of Animal Sciences and Division of Nutritional Sciences, University of Illinois, 1207 West Gregory Drive, Urbana, IL 61801, USA. ${ }^{2}$ Animal and Veterinary Sciences, Clemson University, 146 Poole Agricultural Center, Clemson, SC 29634, USA. ${ }^{3}$ Department of Health Science, Interdepartmental Services Centre of Veterinary for Human and Animal Health, Magna Græcia University of Catanzaro, 88100 Catanzaro, Italy. ${ }^{4}$ Institute of Zootechnics, Faculty of Agriculture, Food and Environmental Science, Università Cattolica del S. Cuore, 29122 Piacenza, Italy.

Received: 4 June 2017 Accepted: 19 December 2017

Published online: 15 January 2018

\section{References}

1. Robinson PH, Garrett JE. Effect of yeast culture (Saccharomyces Cerevisiae) on adaptation of cows to postpartum diets and on lactational performance. J Anim Sci. 1999;77:988-99.

2. Drackley JK, Beaulieu AD, Elliott JP. Responses of milk fat composition to dietary fat or nonstructural carbohydrates in Holstein and Jersey cows. J Dairy Sci. 2001;84:1231-7.

3. Grummer RR. Impact of changes in organic nutrient metabolism on feeding the transition dairy cow. J Anim Sci. 1995;73:2820-33.

4. McNamara JP. Regulation of adipose tissue metabolism in support of lactation. J Dairy Sci. 1991;74:706-19.

5. Sumner-Thomson JM, Vierck JL, McNamara JP. Differential expression of genes in adipose tissue of first-lactation dairy cattle. J Dairy Sci. 2011;94:361-9.

6. Bell AW. Regulation of organic nutrient metabolism during transition from late pregnancy to early lactation. J Anim Sci. 1995;73:2804-19.

7. Drackley JK. Foundation scholar award. Biology of dairy cows during the transition period: the final frontier? J Dairy Sci. 1999;82:2259-73.

8. Gillund P, Reksen O, Grohn YT, Karlberg K. Body condition related to ketosis and reproductive performance in Norwegian dairy cows. J Dairy Sci. 2001;84:1390-6.

9. Treacher RJ, Reid IM, Roberts CJ. Effect of body condition at calving on the health and performance of dairy-cows. Anim Prod. 1986;43:1-6.

10. Bernabucci U, Ronchi B, Lacetera N, Nardone A. Influence of body condition score on relationships between metabolic status and oxidative stress in periparturient dairy cows. J Dairy Sci. 2005;88:2017-26.

11. Ozata M, Mergen M, Oktenli C, Aydin A, Sanisoglu SY, Bolu E, et al. Increased oxidative stress and hypozincemia in male obesity. Clin Biochem. 2002;35:627-31.

12. Morrow JDI. Oxidant stress a connection between obesity and atherosclerosis? Arterioscler Thromb Vasc Biol. 2003:23:368-70.

13. Batistel F, Arroyo JM, Bellingeri A, Wang L, Saremi B, Parys C, et al. Ethylcellulose rumen-protected methionine enhances performance during the periparturient period and early lactation in Holstein dairy cows. J Dairy Sci. 2017; 100:7455-67

14. Ji P, Osorio JS, Drackley JK, Loor JJ. Overfeeding a moderate energy diet prepartum does not impair bovine subcutaneous adipose tissue insulin signal transduction and induces marked changes in peripartal gene network expression. J Dairy Sci. 2012;95:4333-51.
15. Loor JJ, Everts RE, Bionaz M, Dann HM, Morin DE, Oliveira R, et al. Nutritioninduced ketosis alters metabolic and signaling gene networks in liver of periparturient dairy cows. Physiol Genomics. 2007;32:105-16.

16. Vailati Riboni M, Meier S, Priest NV, Burke CR, Kay JK, McDougall S, et al. Adipose and liver gene expression profiles in response to treatment with a nonsteroidal antiinflammatory drug after calving in grazing dairy cows. J Dairy Sci. 2015;98:3079-85.

17. Vailati-Riboni M, Kanwal M, Bulgari O, Meier S, Priest NV, Burke CR, et al. Body condition score and plane of nutrition prepartum affect adipose tissue transcriptome regulators of metabolism and inflammation in grazing dairy cows during the transition period. J Dairy Sci. 2016;99:758-70.

18. Bionaz M, Loor JJ. ACSL1, AGPAT6, FABP3, LPIN1, and SLC27A6 are the most abundant isoforms in bovine mammary tissue and their expression is affected by stage of lactation. J Nutr. 2008;138:1019-24.

19. Duncan RE, Ahmadian M, Jaworski K, Sarkadi-Nagy E, Sul HS. Regulation of lipolysis in adipocytes. Annu Rev Nutr. 2007;27:79-101.

20. Morak M, Schmidinger $H$, Riesenhuber $G$, Rechberger GN, Kollroser $M$ Haemmerle G, et al. Adipose triglyceride lipase (ATGL) and hormonesensitive lipase (HSL) deficiencies affect expression of lipolytic activities in mouse adipose tissues. Mol Cell Proteomics. 2012;11:1777-89.

21. Kraemer FB, Shen WJ. Hormone-sensitive lipase: control of intracellular tri-(di-)acylglycerol and cholesteryl ester hydrolysis. J Lipid Res. 2002;43: 1585-94.

22. Arita Y, Kihara S, Ouchi N, Takahashi M, Maeda K, Miyagawa J, et al. Paradoxical decrease of an adipose-specific protein, adiponectin, in obesity. 1999. Biochem Biophys Res Commun. 2012;425:560-4.

23. De Koster J, Urh C, Hostens M, Van den Broeck W, Sauerwein H, Opsomer G. Relationship between serum adiponectin concentration, body condition score, and peripheral tissue insulin response of dairy cows during the dry period. Domest Anim Endocrinol. 2017:59:100-4

24. De Koster JD, Opsomer G. Insulin resistance in dairy cows. Vet Clin North Am Food Anim Pract. 2013;29:299-322.

25. Sevillano J, de Castro J, Bocos C, Herrera E, Ramos MP. Role of insulin receptor substrate-1 serine 307 phosphorylation and adiponectin in adipose tissue insulin resistance in late pregnancy. Endocrinology. 2007; 148:5933-42.

26. Nakamura MT, Yudell BE, Loor JJ. Regulation of energy metabolism by longchain fatty acids. Prog Lipid Res. 2014;53:124-44

27. Serra D, Mera P, Malandrino MI, Mir JF, Herrero L. Mitochondrial fatty acid oxidation in obesity. Antioxid Redox Signal. 2013;19:269-84.

28. Halestrap AP, Wilson MC. The monocarboxylate transporter family-role and regulation. IUBMB Life. 2012;64:109-19.

29. Lebeck J. Metabolic impact of the glycerol channels AQP7 and AQP9 in adipose tissue and liver. J Mol Endocrinol. 2014;52:R165-78.

30. Maeda N, Funahashi T, Hibuse T, Nagasawa A, Kishida K, Kuriyama H, et al. Adaptation to fasting by glycerol transport through aquaporin 7 in adipose tissue. Proc Natl Acad Sci U S A. 2004;101:17801-6.

31. Sauerwein H, Saremi B, Pappritz J, von Soosten D, Meyer U, Danicke S, et al. Short communication: aquaporin-7 mRNA in adipose depots of primiparous and pluriparous dairy cows: long-term physiological and conjugated linoleic acid-induced changes. J Dairy Sci. 2013;96:4508-13.

32. Hara-Chikuma M, Sohara E, Rai T, Ikawa M, Okabe M, Sasaki S, et al. Progressive adipocyte hypertrophy in aquaporin-7-deficient mice: adipocyte glycerol permeability as a novel regulator of fat accumulation. J Biol Chem. 2005;280:15493-6.

33. Nye C, Kim J, Kalhan SC, Hanson RW. Reassessing triglyceride synthesis in adipose tissue. Trends Endocrinol Metab. 2008;19:356-61.

34. Bionaz $\mathrm{M}$, Thering BJ, Loor JJ. Fine metabolic regulation in ruminants via nutrient-gene interactions: saturated long-chain fatty acids increase expression of genes involved in lipid metabolism and immune response partly through PPAR-a activation. Br J Nutr. 2012;107:179-91.

35. Nordberg J, Arner ES. Reactive oxygen species, antioxidants, and the mammalian thioredoxin system. Free Radic Biol Med. 2001;31:1287-312.

36. Sordillo LM, Aitken SL. Impact of oxidative stress on the health and immune function of dairy cattle. Vet Immunol Immunopathol. 2009;128:104-9.

37. Keaney JF Jr, Larson MG, Vasan RS, Wilson PW, Lipinska I, Corey D, et al. Obesity and systemic oxidative stress: clinical correlates of oxidative stress in the Framingham study. Arterioscler Thromb Vasc Biol. 2003:23:434-9.

38. Fernandez-Sanchez A, Madrigal-Santillan E, Bautista M, Esquivel-Soto J, Morales-Gonzalez A, Esquivel-Chirino C, et al. Inflammation, oxidative stress, and obesity. Int J Mol Sci. 2011;12:3117-32. 
39. Hu Y, Rosen DG, Zhou Y, Feng L, Yang G, Liu J, et al. Mitochondrial manganese-superoxide dismutase expression in ovarian cancer: role in cell proliferation and response to oxidative stress. J Biol Chem. 2005; 280:39485-92

40. Medzhitov R. Toll-like receptors and innate immunity. Nat Rev Immunol. 2001;:1:135-45.

41. Shi H, Kokoeva MV, Inouye K, Tzameli I, Yin H, Flier JS. TLR4 links innate immunity and fatty acid-induced insulin resistance. J Clin Invest. 2006;116: 3015-25.

42. Contreras GA, Sordillo LM. Lipid mobilization and inflammatory responses during the transition period of dairy cows. Comp Immunol Microbiol Infect Dis. 2011;34:281-9.

43. Nishimoto S, Fukuda D, Higashikuni Y, Tanaka K, Hirata Y, Murata C, et al. Obesity-induced DNA released from adipocytes stimulates chronic adipose tissue inflammation and insulin resistance. Sci Adv. 2016;2:e1501332.

Submit your next manuscript to BioMed Central and we will help you at every step:

- We accept pre-submission inquiries

- Our selector tool helps you to find the most relevant journal

- We provide round the clock customer support

- Convenient online submission

- Thorough peer review

- Inclusion in PubMed and all major indexing services

- Maximum visibility for your research

Submit your manuscript at www.biomedcentral.com/submit
Biomed Central 